OPEN ACCESS

Edited by:

Elizabeth L. Hartland, University of Melbourne, Australia

Reviewed by: Marina Santic', University of Rijeka, Croatia

Michele S. Swanson,

University of Michigan, USA

${ }^{*}$ Correspondence:

Sébastien P. Faucher sebastien.faucher2@mcgill.ca

Received: 19 July 2016 Accepted: 12 September 2016 Published: 28 September 2016

Citation:

Li L and Faucher SP (2016) The Membrane Protein LasM Promotes

the Culturability of Legionella pneumophila in Water.

Front. Cell. Infect. Microbiol. 6:113.

doi: 10.3389/fcimb.2016.00113

\section{The Membrane Protein LasM Promotes the Culturability of Legionella pneumophila in Water}

\author{
Laam Li and Sébastien P. Faucher* \\ Department of Natural Resource Sciences, Faculty of Agricultural and Environmental Sciences, McGill University, Montreal, \\ QC, Canada
}

The water-borne pathogen Legionella pneumophila $(L p)$ strongly expresses the Ipg1659 gene in water. This gene encodes a hypothetical protein predicted to be a membrane protein using in silico analysis. While no conserved domains were identified in Lpg1659, similar proteins are found in many Legionella species and other aquatic bacteria. RT-qPCR showed that lpg1659 is positively regulated by the alternative sigma factor RpoS, which is essential for $L p$ to survive in water. These observations suggest an important role of this novel protein in the survival of $L p$ in water. Deletion of Ipg1659 did not affect cell morphology, membrane integrity or tolerance to high temperature. Moreover, Ipg1659 was dispensable for growth of $L p$ in rich medium, and during infection of the amoeba Acanthamoeba castellanii and of THP-1 human macrophages. However, deletion of Ipg1659 resulted in an early loss of culturability in water, while over-expression of this gene promoted the culturability of $L p$. Therefore, these results suggest that lpg1659 is required for $L p$ to maintain culturability, and possibly long-term survival, in water. Since the loss of culturability observed in the absence of Lpg1659 was complemented by the addition of trace metals into water, this membrane protein is likely a transporter for acquiring essential trace metal for maintaining culturability in water and potentially in other metal-deprived conditions. Given its role in the survival of $L p$ in water, Lpg1659 was named LasM for Legionella aquatic survival membrane protein.

Keywords: Legionella pneumophila, freshwater, survival, Ipg1659, membrane protein, metal transporter

\section{INTRODUCTION}

Legionella pneumophila $(L p)$ is a water-borne opportunistic pathogen that can infect human alveolar macrophages, resulting in a severe form of pneumonia called Legionnaires' disease (Fields et al., 2002). Recent years have seen an increase in the incidence of sporadic cases and outbreaks of Legionnaires' disease around the world, mostly associated with Legionella-contaminated man-made water systems (European Centre for Disease Prevention and Control, 2013; Phin et al., 2014).Since the major mode of transmission is through water, the dynamics of $L p$ in freshwater have been studied extensively. It is known that $L p$ replicates only in the presence of sufficient nutrients or permissive hosts (Fields et al., 2002). Under nutrient limitation, $L p$ can survive for a prolonged

Abbreviations: Lp, Legionella pneumophila; VBNC, viable but non-culturable; WT, wild-type. 
period of time, up to 1.5 years in some cases, in varying compositions of freshwater including tap water, drinking water and creek water (Skaliy and McEachern, 1979; Schofield, 1985; Lee and West, 1991; Paszko-Kolva et al., 1992; Söderberg et al., 2008).

In an artificial freshwater model, Fraquil, $L p$ had less than a $1-\log$ reduction in $\mathrm{CFU}$ counts after 20 weeks at $25^{\circ} \mathrm{C}(\mathrm{Li}$ et al., 2015; Mendis et al., 2015). Moreover, $L p$ can survive for several months under a range of temperatures, $\mathrm{pH}$ and trace metal concentrations and remain infectious more than 6 months after exposure to Fraquil (Mendis et al., 2015). This ability for long-term survival in different kinds of water and under different conditions allows $L p$ to colonize water systems, and persist until it encounters a suitable host.

A limited number of studies have identified genes that are important for the survival of $L p$ in water. Söderberg et al. (2008) found that $l s p D, l s p E, l s p F$, and $p i l D$, which encode components of the virulence-related type II secretion system, are necessary for $L p$ to survive in water at temperatures below $17^{\circ} \mathrm{C}$. In addition, the alternative sigma factor RpoS, as well as the stringent response regulators RelA and SpoT are required for the survival of $L p$ in water at $25^{\circ} \mathrm{C}$ (Trigui et al., 2014). In order to identify additional genes contributing to survival in water, we previously conducted a microarray analysis comparing the transcriptome of $L p$ exposed to water to that of Lp grown in rich medium (Li et al., 2015). Since bacteria tend to respond to environmental changes via transcriptomic reorganization (Ishihama, 2000; Hecker et al., 2009), genes that are highly up-regulated upon water exposure could be crucial for the successful adaptation and survival of $L p$ in water systems. Using this approach, we found that one highly up-regulated gene, $b d h A$, encoding 3-hydroxybutyrate dehydrogenase, is important for the long-term survival of $L p$ in water at $37^{\circ} \mathrm{C}$ (Li et al., 2015).

Due to the success of this approach, we selected another highly up-regulated gene, $\operatorname{lpg} 1659$, for further characterization. $\operatorname{lpg} 1659$ was significantly up-regulated in $L p$ exposed to water for 2 and 6 h (Li et al., 2015). No previous studies have characterized lpg1659, which encodes a hypothetical protein with no putative functions. Nevertheless, we found that this protein is highly conserved in many Legionella species, as well as other aquatic bacteria. Therefore, we hypothesized that $l p g 1659$ is important for $L p$ to survive in freshwater. A deletion mutant of $\operatorname{lpg} 1659$ was used to better understand its role with respect to cell structure, survival in water and growth of $L p$. We found that Lpg1659 plays a role in the long-term culturability of $L p$ upon water exposure at 37 and $42^{\circ} \mathrm{C}$. Evidence presented here suggests that it likely acts as an ion transporter, facilitating the uptake of one or more essential trace metal ions. Based on our results, the lpg1659 gene was named las $M$ for Legionella aquatic survival membrane protein.

\section{METHODS}

\section{Bacterial Strains and Culture Conditions}

All $L p$ strains used in this study were constructed from JR32, a streptomycin resistant derivative of $L p$ Philadelphia-1 (Sadosky et al., 1993). The constitutively competent KS79 strain, derived from JR32, was used for the construction of the lpg1659 mutant strain (de Felipe et al., 2008). Unless specified otherwise, Lp was grown on ACES-Buffered Charcoal Yeast Extract agar supplemented with $0.4 \mathrm{mg} \mathrm{ml}^{-1} \mathrm{~L}$-cysteine, $0.25 \mathrm{mg} \mathrm{ml}^{-1}$ ferric pyrophosphate and $0.1 \% \underline{\alpha}$-ketoglutarate (i.e., BCYE $\alpha$ agar) at $37^{\circ} \mathrm{C}$ for 3 days (Feeley et al., 1979; Edelstein, 1981). This medium was further supplemented with $25 \mu \mathrm{g} \mathrm{ml}^{-1}$ kanamycin or $5 \mu \mathrm{g} \mathrm{ml}^{-1}$ chloramphenicol, when necessary. Escherichia coli strains derived from $\mathrm{DH} 5 \alpha$ were grown on Luria-Bertani agar at $37^{\circ} \mathrm{C}$ overnight and was supplemented with $25 \mu \mathrm{g} \mathrm{m} \mathrm{m}^{-1}$ chloramphenicol, when necessary. Descriptions of the bacterial strains used in this study can be found in Table $\mathbf{1}$.

\section{Construction of Mutant, Complemented, and Over-Expression Strains}

To construct the lpg1659 deletion mutant strain SPF248 $(\Delta$ las $M), 1 \mathrm{~kb}$ length sequences upstream and downstream of lpg1659 were first amplified from the wild-type (WT) strain KS79 by PCR using Taq polymerase (Invitrogen), with the primer sets 1659_UpF/1659_UpR and 1659_DownF/1659_DownR, respectively. The kanamycin cassette was amplified from pSF6 with the primer set $\mathrm{Kn}-\mathrm{F} / \mathrm{Kn}-\mathrm{R}$, purified and further amplified with the primer set $1659 \_\mathrm{KnF} / 1659 \_\mathrm{KnR}$ to obtain a $1 \mathrm{~kb}$ kanamycin fragment where the $5^{\prime}$ end is complementary to the $3^{\prime}$ end of the upstream fragment, and $3^{\prime}$ end is complementary to the $5^{\prime}$ end of downstream fragment. A $3 \mathrm{~kb}$ mutant allele was amplified using the three $1 \mathrm{~kb}$ fragments as template, Phusion DNA polymerase (NEB) and the primer set 1659_UpF/1659_DownR. The purified amplicon was then introduced into KS79 through natural transformation (de Felipe et al., 2008). The recombinants were selected for kanamycin resistance, and successful replacement of the target gene by the kanamycin cassette was validated by PCR.

To construct the pSF83 plasmid (plasM) for complementation, the target gene lpg1659 together with $500 \mathrm{bp}$ region upstream of the translation start site was amplified from KS79 using the primer set Com1659F2_SacI/Com1659R_XbaI. The amplicon and the plasmid pXDC39 were both digested with SacI and XbaI (NEB) and ligated using T4 DNA ligase (NEB). The ligation mixture was transformed into competent E. coli $\mathrm{DH} 5 \alpha$ and the transformants were selected for chloramphenicol resistance. Correct insertion of the amplicon in the plasmid extracted from transformants was validated by PCR using the primer set pXDC39-F/Com1659R_XbaI. This pSF83 plasmid was then introduced into the mutant strain $\Delta$ las $M$ by electroporation as described previously (Chen et al., 2006), so as to construct the complemented strain SPF294 ( $\Delta$ las $M+$ plasM). The recombinants were selected for kanamycin and chloramphenicol resistance before validation by PCR.

To construct the pSF73 plasmid (plasMi) for over-expression, the target gene lpg1659 was first amplified from KS79 using the primer set Com1659F_SacI/Com1659R_XbaI. The amplicon and the plasmid pMMB207c were both digested with SacI and $\mathrm{XbaI}(\mathrm{NEB})$ and ligated with T4 DNA ligase (NEB). The ligation mixture was transformed into competent E. coli $\mathrm{DH} 5 \alpha$ and the transformants were selected for chloramphenicol resistance. The presence of the insert $(\operatorname{lpg} 1659)$ in the plasmid extracted 
TABLE 1 | Bacterial strains used in this study.

\begin{tabular}{|c|c|c|}
\hline Name & Relevant genotype & References \\
\hline \multicolumn{3}{|c|}{ LEGIONELLA PNEUMOPHILA } \\
\hline JR32 & $\mathrm{r}^{-} \mathrm{m}^{+}, \mathrm{Sm} \mathrm{R}^{\mathrm{R}}$ & Sadosky et al., 1993 \\
\hline LELA3118 (dotA mutant) & JR32 dotA::Tn903dlllacZ & Sadosky et al., 1993 \\
\hline LM1376 (rpoS mutant) & JR32 rpoS::Tn903dGent, GmR & Hales and Shuman, 1999 \\
\hline SPF294 (4lasM+plasM) & SPF248 pSF83, $\mathrm{Kn}^{\mathrm{R}} \mathrm{Cm}^{\mathrm{R}}$ & This work \\
\hline SPF298 (WT+plasMi) & KS79 pSF73, CmR & This work \\
\hline \multicolumn{3}{|l|}{ ESCHERICHIA COLI } \\
\hline $\mathrm{DH} 5 \alpha$ & supE44 $\Delta / a c \cup 169$ ( $\$ 80$ lacZ $\Delta \mathrm{M} 15)$ hsdR17 recA1 endA1 gyrA96 thi-1 relA1 & Invitrogen \\
\hline pMMB207C & $\mathrm{DH} 5 \alpha, \Delta m o b A, \mathrm{Cm}^{\mathrm{R}}$ & Charpentier et al., 2008 \\
\hline pXDC39 & DH5 $\alpha$, pMMB207c, $\Delta$ Ptac, $\Delta / a c l, \mathrm{Cm}^{R}$ & Xavier Charpentier \\
\hline
\end{tabular}

from transformants was validated by PCR using the primer set PromF/Com1659R_XbaI. This pSF73 plasmid was then introduced into KS79 by electroporation in order to construct the over-expression strain SPF298 (WT+plasMi). The recombinants were selected for kanamycin and chloramphenicol resistance before validation by PCR. The primer sequences are listed in Table 2.

\section{RT-qPCR}

JR32, the rpoS mutant and the complemented strain SPF176 were first suspended in ACES-buffered Yeast Extract (AYE) broth at an initial $\mathrm{OD}_{600}$ of 0.1 . Fifty milliliter cultures of JR32, rpoS mutant, SPF176 (prpoS OFF) and SPF176 induced with $0.5 \mathrm{mM}$ IPTG (prpoS ON) were grown in $250 \mathrm{ml}$ Erlenmeyer flasks at $37^{\circ} \mathrm{C}$ shaking $(250 \mathrm{rpm})$ to exponential phase $\left(\mathrm{OD}_{600}\right.$ of 1.0). Each culture was then centrifuged and washed with Fraquil three times before suspending in Fraquil to an $\mathrm{OD}_{600}$ of 1.0. Fraquil is an artificial freshwater medium that does not support growth but allows long-term survival of $L p$ ( $\mathrm{Li}$ et al., 2015; Mendis et al., 2015).The composition of Fraquil is $0.25 \mu \mathrm{M} \mathrm{CaCl}_{2}, 0.15 \mu \mathrm{M} \mathrm{MgSO}_{4}, 0.15 \mu \mathrm{M} \mathrm{NaHCO}, 10 \mathrm{nM}$ $\mathrm{K}_{2} \mathrm{HPO}_{4}, 0.1 \mu \mathrm{M} \mathrm{NaNO}, 10 \mathrm{nM} \mathrm{FeCl}_{3}, 1 \mathrm{nM} \mathrm{CuSO}$, $0.22 \mathrm{nM}$ $\left(\mathrm{NH}_{4}\right)_{6} \mathrm{Mo}_{7} \mathrm{O}_{24}, 2.5 \mathrm{nM} \mathrm{CoCl}_{2}, 23 \mathrm{nM} \mathrm{MnCl}_{2}$, and $4 \mathrm{nM} \mathrm{ZnSO}_{4}$ in ultra-pure Milli-Q water (Morel et al., 1975). Thirty milliliter of each suspension was transferred to $125 \mathrm{ml}$ Erlenmeyer flask and incubated at $37^{\circ} \mathrm{C}$ shaking for $6 \mathrm{~h}$. Samples were then collected and RNA was extracted as described previously (Li et al., 2015). One microgram of purified RNA was used for reverse transcription reactions along with a negative control without reverse transcriptase. For qPCR reactions, the $16 \mathrm{~S}$ rRNA genespecific primer set 16s_QF/16s_QF and the lpg1659 gene-specific primer set 1659_QF/1659_QR were designed with the IDT primer design software (https://www.idtdna.com/Primerquest/), and their amplification efficiency were proven to be $>85 \%$ (data
TABLE 2 | Primer sequences used in this study.

\begin{tabular}{|c|c|}
\hline Name & Sequence $\left(5^{\prime}-3^{\prime}\right)^{*}$ \\
\hline 1659_UpF & CAATCAGAACAAGGTGTGTATGG \\
\hline 1659_UpR & $\begin{array}{l}\text { CAGTCTAGCTATCGCCATGTACGATGAGTACTGAATT } \\
\text { CCTGC }\end{array}$ \\
\hline 1659_DownF & $\begin{array}{l}\text { GATGCTGAAGATCAGTTGGGTCACGTCCTATCACATTC } \\
\text { TATTACTC }\end{array}$ \\
\hline 1659_DownR & AGATCGATGAAGGCTTGTAGC \\
\hline 1659_KnF & $\begin{array}{l}\text { GCAGGAATTCAGTACTCATCGTACATGGCGATAGCT } \\
\text { AGACTG }\end{array}$ \\
\hline 1659_KnR & $\begin{array}{l}\text { GAGTAATAGAATGTGATAGGACGTGACCCAACTGATCTT } \\
\text { CAGCATC }\end{array}$ \\
\hline 1659_QF & CGGTCACTCTITGGTATATGTC \\
\hline 1659_QR & CTGATTGACTGGATCGAACATC \\
\hline 16s_QF & AGAGATGCATTAGTGCCTTCGGGA \\
\hline 16s_QR & ACTAAGGATAAGGGTTGCGCTCGT \\
\hline Com1659F_Sacl & CCGGAGCTCGCAGGAATTCAGTACTCATCG \\
\hline Com1659F2_Sacl & CCGGAGCTCCACCTTCAGATTGTTAGTCGC \\
\hline Com1659R_Xbal & CGCTCTAGAGAGTAATAGAATGTGATAGGACG \\
\hline $\mathrm{Kn}-\mathrm{F}$ & TACATGGCGATAGCTAGACTG \\
\hline $\mathrm{Kn}-\mathrm{R}$ & ACCCAACTGATCTTCAGCATC \\
\hline pXDC39-F & GCTTCCACAGCAATGGCATCC \\
\hline PromF & CGTATAATGTGTGGAATTGTGAG \\
\hline
\end{tabular}

*The underlined bases indicate restriction sites.

not shown). qPCR was performed on an $\mathrm{iQ}^{\mathrm{TM}} 5$ Multicolor RealTime PCR Detection System (Bio-Rad) using iTaq universal SYBR green supermix (Bio-Rad) according to the manufacturer's protocol. The 16SrRNA gene was used as the reference gene to normalize the data. Fold change was calculated as described previously (Livak and Schmittgen, 2001) and are presented as $\log _{2}$ ratios. 


\section{Bioinformatics Analysis}

The hypothetical protein (accession number: YP_095686.1) encoded by las $M$ was compared to proteins encoded by other bacteria using Standard Protein BLAST (http://blast.ncbi.nlm. nih.gov/Blast.cgi?PAGE=Proteins). The NCBI CD-search was used to identify any conserved domains present in the LasM protein. Three servers from the CBS Prediction Servers (http:// www.cbs.dtu.dk/services/) were then used to predict the putative function(s) of LasM. First, TMHMM Server v.2.0 was used to predict transmembrane helices (Sonnhammer et al., 1998; Krogh et al., 2001). Second, SignalP 4.1 Server was used to predict the presence and location of signal peptides (Petersen et al., 2011). Lastly, ProtFun 2.2 Server was used to predict cellular role, enzyme class as well as the gene ontology category based on the amino acid sequence (Jensen et al., 2002, 2003).

\section{Microscopic Examination of Cell Morphology}

The WT strain KS79 and the mutant strain $\Delta$ lasM were suspended in Fraquil at an $\mathrm{OD}_{600}$ of 1.0. Immediately after suspension, a wet mount was prepared and viewed at $1000 \times$ magnification using digital microscopy (Nikon Eclipse 80i). Images of 10 random microscopic fields were captured for each strain using the NIS Element software (Nikon Instruments, Inc.). The length of 10 cells in each image was estimated using the ImageJ software in order to determine the average cell length.

\section{Extracellular Growth Assay}

The KS79 and $\Delta$ lasM strains were suspended in AYE broth at an $\mathrm{OD}_{600}$ of 0.1. Twenty-five $\mathrm{ml}$ of each culture was transferred into three $125 \mathrm{ml}$ Erlenmeyer flasks and grown at $37^{\circ} \mathrm{C}$ shaking. The $\mathrm{OD}_{600}$ of each culture was measured by a spectrophotometer once every $4 \mathrm{~h}$ for a period of $32 \mathrm{~h}$.

\section{Cell Lines and Infection Assays}

The amoeba Acanthamoeba castellanii was grown to confluence in $20 \mathrm{ml}$ of PYG broth (Moffat and Tompkins, 1992) in a $75 \mathrm{~cm}^{2}$ tissue culture flask (Sarstedt) at $30^{\circ} \mathrm{C}$. Before infection with $L p$, the old medium with non-adherent amoebae was replaced with $10 \mathrm{ml}$ of fresh PYG broth. The flask was then shaken sharply to release the adherent amoebae into the medium. This suspension was enumerated and diluted to $5 \times 10^{5}$ cells per $\mathrm{ml}$. One $\mathrm{ml}$ was placed into each well of a 24 -well plate (Sarstedt). The amoebae were allowed to adhere for $2 \mathrm{~h}$ before the medium was replaced with Ac buffer, which does not support the growth of $L p$ (Moffat and Tompkins, 1992). The plate was incubated at $30^{\circ} \mathrm{C}$ for another $2 \mathrm{~h}$ before infection.

The human monocyte-like cell line THP-1 was grown in $30 \mathrm{ml}$ of RPMI 1640 (Life Technologies) supplemented with 10\% fetal bovine serum and $2 \mathrm{mM}$ glutamine at $37^{\circ} \mathrm{C}$ under $5 \% \mathrm{CO}_{2}$ (Kim et al., 2009). Three days prior to infection, $1 \mathrm{ml}$ of THP-1 culture $\left(5 \times 10^{5}\right.$ cells per $\left.\mathrm{ml}\right)$ was placed into each well of a 24 -well plate (Sarstedt) and treated with $1 \times 10^{-7} \mathrm{M}$ phorbol 12 -myristate 13-acetate (PMA) (Fisher Scientific) to induce maturation toward adherent macrophage-like cells. Subsequently, the medium was replaced by fresh RPMI without PMA $2 \mathrm{~h}$ before infection with $L p$.
For the infection assays, the KS79, $\Delta$ las $M$, and $\operatorname{dot} A$ mutant were suspended in AYE broth at an $\mathrm{OD}_{600}$ of 0.1 and then, diluted 10 -fold to approximately $2.5 \times 10^{6}$ cells per ml. The dotA mutant is defective for intracellular growth (Roy and Isberg, 1997) and was used as a negative control. Two microliter of each bacterial suspension was added to three replicate wells of $A$. castellanii and THP- 1 cells, resulting in an MOI of 0.1 . The A. castellanii infection plate was incubated at $30^{\circ} \mathrm{C}$ and the intracellular growth of each strain was determined by CFU counts on BCYE $\alpha$ agar at $24 \mathrm{~h}$ intervals for 7 days; whereas the THP- 1 infection plate was incubated at $37^{\circ} \mathrm{C}$ under $5 \% \mathrm{CO}_{2}$, and the intracellular growth was monitored at $24 \mathrm{~h}$ intervals for 5 days.

\section{Survival Assays in Water}

Strains grown on BCYE $\alpha$ agar were washed three times with Fraquil and suspended in fresh Fraquil at an $\mathrm{OD}_{600}$ of 0.1. One milliliter of bacterial suspension was added to $4 \mathrm{ml}$ of fresh Fraquil in a $25 \mathrm{~cm}^{2}$ plastic flask (Sarstedt). For each strain, three replicate flasks were incubated at 25,37 , and $42^{\circ} \mathrm{C}$, and $\mathrm{CFU}$ counts were measured once per 3 weeks, once per 2 weeks and once per week, respectively. In addition, membrane integrity of the samples incubated at $42^{\circ} \mathrm{C}$ for 7 weeks was determined by Live/Dead staining and flow cytometry, using freshly grown KS79 as the live control and KS79 boiled in a water bath for $10 \mathrm{~min}$ as the dead control, as described previously (Li et al., 2015).

For the survival assay using Fraquil containing10 times trace metals, the final salt and trace metal concentration is $0.25 \mu \mathrm{M} \mathrm{CaCl}, 0.15 \mu \mathrm{M} \mathrm{MgSO}_{4}, 0.15 \mu \mathrm{M} \mathrm{NaHCO}, 10 \mathrm{nM}$ $\mathrm{K}_{2} \mathrm{HPO}_{4}, 0.1 \mu \mathrm{M} \mathrm{NaNO}, 0.1 \mu \mathrm{M} \mathrm{FeCl}, 10 \mathrm{nM} \mathrm{CuSO}{ }_{4}, 2.2$ $\mathrm{nM}\left(\mathrm{NH}_{4}\right)_{6} \mathrm{Mo}_{7} \mathrm{O}_{24}, 25 \mathrm{nM} \mathrm{CoCl}_{2}, 0.23 \mu \mathrm{M} \mathrm{MnCl}_{2}$, and $40 \mathrm{nM}$ $\mathrm{ZnSO}_{4}$.

\section{Heat Tolerance Assays}

To test tolerance to heat shock, the KS79 and $\Delta l a s M$ strains were suspended in Fraquil at an $\mathrm{OD}_{600}$ of 0.1. One $\mathrm{ml}$ of each strain was aliquoted into $13 \mathrm{ml}$ tubes (Sarstedt) in triplicate. Tubes were acclimated to $25^{\circ} \mathrm{C}$ for $24 \mathrm{~h}$ and then, transferred into a water bath set to $55^{\circ} \mathrm{C}$. Samples were taken before, after $0.5 \mathrm{~h}$ and after $1 \mathrm{~h}$ of heat shock to determine the changes in CFU counts.

To test growth at an elevated temperature, the KS79 and $\Delta$ las $M$ strains were suspended in AYE broth at an $\mathrm{OD}_{600}$ of 0.1. Twenty-five milliliter of each culture was transferred into three $125 \mathrm{ml}$ Erlenmeyer flasks and grown at $42^{\circ} \mathrm{C}$ shaking. The $\mathrm{CFU}$ of each strain was monitored daily.

\section{RESULTS}

\section{lasM Is Positively Regulated by RpoS in Water}

In a previous study, we found that las $M$ was significantly up-regulated by more than 6 -fold after $2 \mathrm{~h}\left(\log _{2}\right.$ ratio $\left.=2.66\right)$ and 24 -fold after $6 \mathrm{~h}\left(\log _{2}\right.$ ratio $\left.=4.60\right)$ of exposure to water when compared to a control grown in rich medium (Figure 1A; Li et al., 2015). RpoS is an alternative sigma factor and a stress response regulator important for the survival of $L p$ in water (Trigui et al., 2014). In order to test whether the expression of lasM is controlled by RpoS, RT-qPCR was performed using RNA 

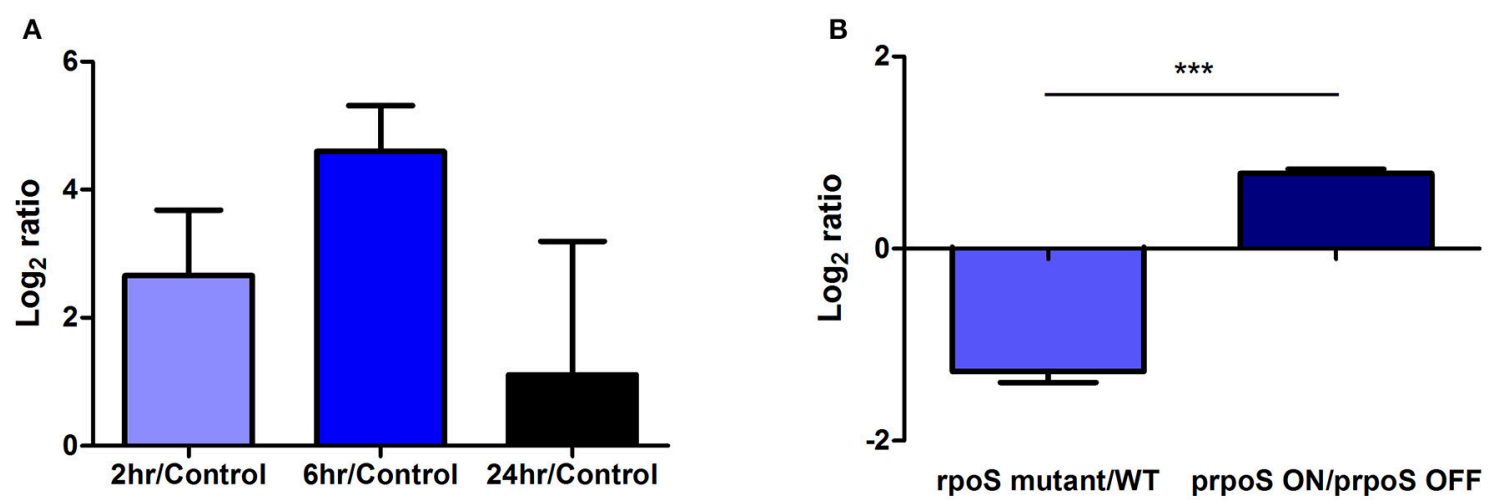

FIGURE 1 | LasM is expressed in water and is regulated by RpoS. (A) The expression of lasM based on a transcriptomic analysis of the WT JR32 strain exposed to water for 2, 6, and $24 \mathrm{~h}$ compared to the control grown to exponential phase in rich medium (adapted from Li et al., 2015 published under Creative Commons Attribution 4.0 International License; https://creativecommons.org/licenses/by/4.0/). (B) The RpoS-dependant regulation of lasM in $L p$ exposed to water for $6 \mathrm{~h}$ was assessed by RT-qPCR. The expression of lasM in the rpoS mutant was compared to that in the WT strain. The expression of lasM in the complemented strain where rpoS is induced with $0.5 \mathrm{mM} \mathrm{IPTG} \mathrm{(prpoS} \mathrm{ON)} \mathrm{was} \mathrm{compared} \mathrm{to} \mathrm{that} \mathrm{of} \mathrm{the} \mathrm{non-induced} \mathrm{complement} \mathrm{(prpoS} \mathrm{OFF).} \mathrm{One-tailed} \mathrm{unpaired} \mathrm{Student's} t$-test was used to assess significant differences between the two ratios $\left({ }^{* \star} p<0.0005\right)$. Data shown are the mean and SD of 3 biological replicates.

from the WT, rpoS mutant and complemented strains that were exposed to water. The fold change of the las $M$ transcript upon water exposure was lower in the rpoS mutant compared to the $\mathrm{WT}$, reflected in the negative $\log _{2}$ ratio of -1.3 (Figure 1B). In contrast, induction of RpoS expression in the mutant (prpoS $\mathrm{ON}$ ) resulted in a positive $\log _{2}$ ratio of 0.8 , indicative of an increase in las $M$ expression, when compared to its non-induced counterpart (prpoS OFF). Taken together, these results suggest that the expression of las $M$ is positively regulated by RpoS in water.

\section{LasM Is a Conserved Protein Found in Aquatic Bacteria}

According to the NCBI Protein database, the hypothetical protein encoded by las $M$ is composed of 347 amino acids. Standard Protein BLAST revealed that LasM found in the Philadelphia-1 strain of $L p$ is highly conserved in other strains, such as Paris, Corby, Alcoy and Lens ( $\geq 98 \%$ identity). Other Legionella species that contain a LasM homolog include L. norrlandica ( $87 \%$ identity), L. moravica ( $77 \%$ identity), L. tucsonensis (76\% identity), and L. longbeachae (68\% identity). LasM also shares significant homology (61-63\% identity) with hypothetical or membrane proteins found in Methylophaga nitratireducenticrescens, Methylophaga lonarensis, Moritella dasanensis, Endozoicomonas elysicola, Colwellia psychrerythraea, Marinobacter santoriniensis among others. These bacteria were isolated from various aquatic environments, such as water treatment systems, soda lakes and the Arctic Ocean (Kurahashi and Yokota, 2007; Kim et al., 2008; Handley et al., 2009; Antony et al., 2012; Villeneuve et al., 2013). Therefore, the protein sequence homology suggests that LasM is a conserved protein found not only in Legionella species, but also in other aquatic bacteria.

Since LasM does not harbor any conserved domains, in silico analysis was performed using the CBS Prediction Servers to predict its putative function(s). Eight transmembrane helices were predicted using the TMHMM server (Figure 2), suggesting that LasM is a transmembrane protein. Moreover, its N-terminal is likely to be located on the cytoplasmic side of the membrane $(p=0.99911)$. No potential signal peptides were identified using the SignalP Server, suggesting that LasM is located in the cytoplasmic membrane. The ProtFun Server predicted LasM to be a non-enzyme $(p=0.809)$ involved in "Transport and Binding” ( $p=0.740)$, most likely to be a transporter $(p=0.409)$ among 14 different Gene Ontology categories. Our in silico analysis suggests that LasM is a conserved membrane protein, that may be involved in the transport of an unknown substance as part of its aquatic lifestyle.

\section{Deletion of lasM Does Not Affect Cellular Morphology}

Since LasM is predicted to be a membrane protein, we investigated whether the deletion of las $M$ would alter the cellular morphology of Lp. Microscopic analysis of wet mounts of 3 days old culture suspended in Fraquil shows that both the WT and the las $M$ deletion mutant are rod shaped cells of comparable size (Figures 3A,B). Statistical analysis confirms that there were no significant differences ( $p=0.1659)$ between the cell lengths of the two strains (Figure 3C). These results indicate that the absence of LasM in $L p$ does not affect cell shape or cell size.

\section{LasM Is Dispensable for Growth In vitro and In vivo}

Growth and infection assays were performed to investigate the potential role of LasM in extracellular and intracellular growth. The WT and $\Delta$ las $M$ strains produced similar growth curves in rich medium, suggesting that las $M$ is dispensable for the growth of $L p$ in vitro (Figure 4A). The lag phase of both strains lasted $8 \mathrm{~h}$ and exponential growth occurred between 8 and $20 \mathrm{~h}$, followed by a late post-exponential/stationary phase.

CFU of the WT and $\Delta$ lasM strains increased by 4-log after 7 days of growth within the amoeba A. castellanii 


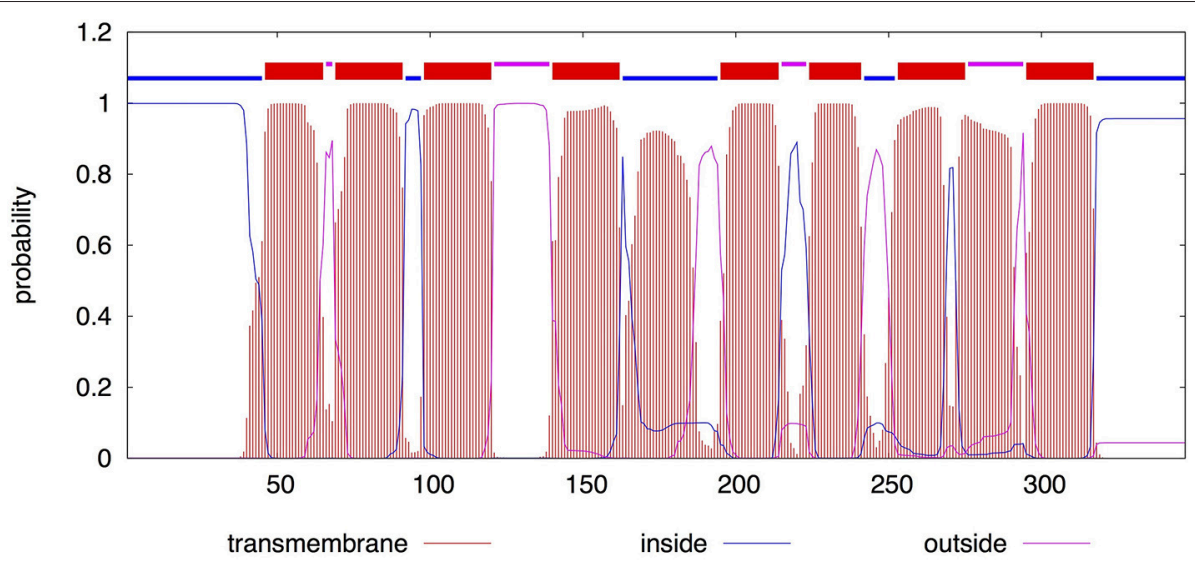

FIGURE 2 | TMHMM posterior probability for LasM. The sequence of LasM was analyzed by TMHMM Server v.2.0. The segmented line on top summarizes the most probable location of the sequence. The lower part shows the probability of belonging to different locations. Red indicates transmembrane regions, blue indicates intracellular portions of the protein and pink indicates extracellular portions.

(Figure 4B). In contrast, both the WT and $\Delta$ las $M$ only produced a 2.5-log increase in CFU counts after 5 days of growth within human macrophage-like THP-1 cells (Figure 4C). As expected, the $\operatorname{dot} A$ mutant that served as a negative control demonstrated a reduction in CFU counts in both infection models (Figures 4B,C). No significant differences were observed between the WT and $\Delta$ las $M$ in both infection assays, showing that deletion of las $M$ does not affect the ability of $L p$ to infect and multiply intracellularly within A. castellanii or within THP-1 cells.

\section{Deletion and Over-Expression of lasM Affects the Culturability of $L p$ in Water}

Since las $M$ is highly up-regulated in $L p$ exposed to water ( $\mathrm{Li}$ et al., 2015) and positively regulated by RpoS, we hypothesized that it may be important for the survival of $L p$ in water. We monitored the changes in CFU counts of the WT, $\Delta$ las $M$ and the complemented strain $(\Delta$ las $M+$ plas $M)$ during long-term exposure to water at three different temperatures. At $25^{\circ} \mathrm{C}$, all three strains survived well, and no significant reduction in $\mathrm{CFU}$ counts was observed after 24 weeks in water (Figure 5A). In contrast, the CFU of all three strains dropped below detection limit after 22 weeks of water exposure at $37^{\circ} \mathrm{C}$ (Figure 5B). The $\Delta$ las $M$ strain had a faster reduction in CFU count and a significantly lower CFU than the WT starting at week 12 . The complemented strain survived as well as the WT, suggesting that las $M$ is indeed important for $L p$ to maintain culturability in water. Similar trend was observed in the strains exposed to $42^{\circ} \mathrm{C}$, where an early loss in culturability was only observed in $\Delta$ las $M$ but not in the WT or the complemented strain (Figure 5C). At this temperature, the CFU counts of all three strains decreased more rapidly than at $37^{\circ} \mathrm{C}$, dropping below the detection limit after only 5 weeks of water exposure.

Since the deletion of lasM resulted in an early loss of culturability at both 37 and $42^{\circ} \mathrm{C}$, we hypothesized that over-expression of this gene in the WT would promote the culturability of $L p$ in water. Given that the difference in culturability between the WT and $\Delta$ las $M$ strains was the greatest at $42^{\circ} \mathrm{C}$, the effect of las $M$ over-expression was tested at this temperature. A plasmid containing an inducible Ptac promoter preceding the las $M$ ORF was constructed and introduced into the WT strain (WT+plasMi). Under non-inducing conditions $(\mathrm{WT}+$ plasMi OFF), the decline in CFU counts over time was similar to the WT strain (Figure 5F). Interestingly, overexpression of LasM using IPTG (WT+plasMi ON) increased the culturability of $L p$ by 1 week. This further supports the notion that las $M$ is important for $L p$ to maintain culturability in water.

\section{Deletion of lasM Does Not Affect the Culturability of $L p$ in Water Containing Excess Trace Metals}

Given that LasM was predicted to be a membrane protein involved in "transport and binding" and since it was found to be important for maintaining the culturability of $L p$ in water, we hypothesized that this protein could be involved in acquiring essential nutrients that are present in low amounts in water, such as trace metals. Therefore, we tested the culturability of the WT, $\Delta$ las $M$ and the complemented strain $(\Delta$ las $M+$ plasM $)$ in water containing 10 times of trace metals at $42^{\circ} \mathrm{C}$. Surprisingly, the CFU counts declined at the same rate for all three strains throughout the 7 weeks of exposure, and the mutant no longer demonstrated an early loss of culturability as observed previously (Figures 5C,D). Therefore, LasM does not alter the kinetics of culturability over time when excess trace metals are present in water.

\section{Deletion of lasM Does Not Affect Membrane Integrity of $L p$ Exposed to Water}

After exposure to water at $42^{\circ} \mathrm{C}$ for 7 weeks, we analyzed the cell status of the WT, $\Delta$ las $M$, and the complemented strain ( $\Delta$ las $M+$ plasM) using Live/Dead staining and flow cytometry. Live/Dead staining differentiates between dead cells that have a damaged membrane and viable cells with an intact membrane. In this case, over $90 \%$ of each strain under investigation stained as 
A

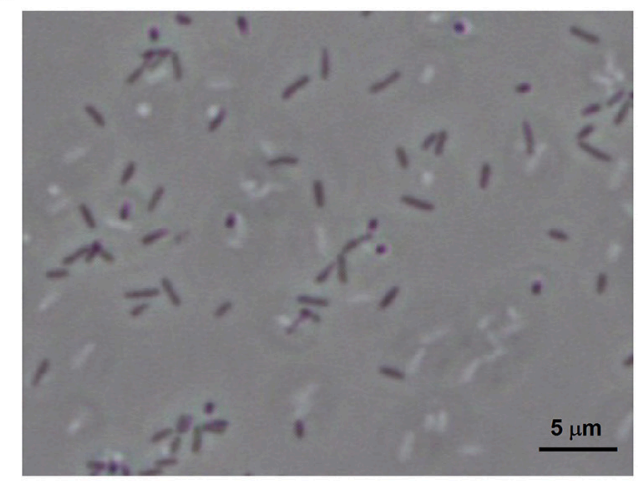

B

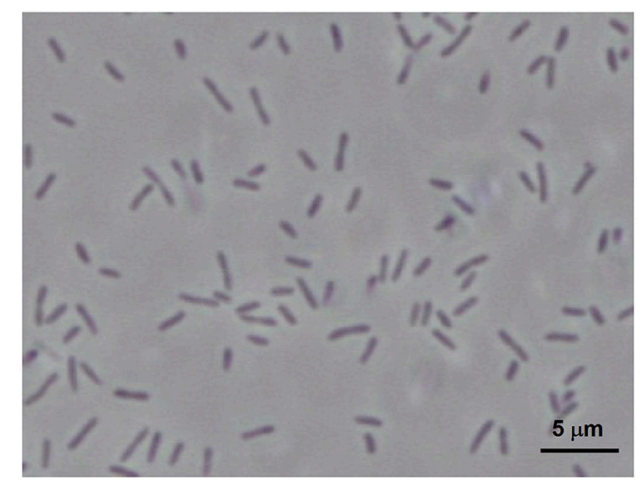

C

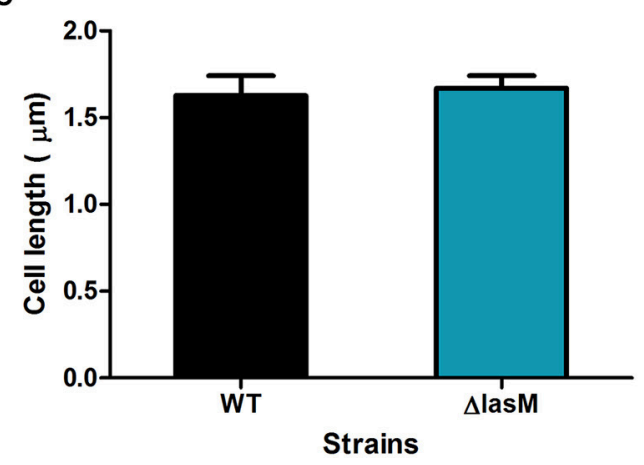

FIGURE 3 | Deletion of lasM does not affect cell morphology or cell size. A wet mount image of (A) the WT strain and (B) $\Delta$ lasM was observed under $1000 \times$ magnification. (C) The cell length of the WT strain and $\Delta$ lasM was estimated using ImageJ. Data shown are the mean and SD of the length of 10 cells per microscopic image in 10 analyzed images $(n=100)$.

viable cells, and less than $2 \%$ of each population were stained as dead (Figure 5E). This data shows that the absence of membrane protein LasM does not significantly affect the membrane integrity of $L p$ after exposure to water.

\section{Deletion of lasM Does Not Affect the Tolerance of $L p$ to High Temperature}

Since early loss of culturability of the las $M$ mutant was only observed at 37 and $42^{\circ} \mathrm{C}$ but not at $25^{\circ} \mathrm{C}$, we investigated whether the mutant was sensitive to elevated temperatures. First,
A

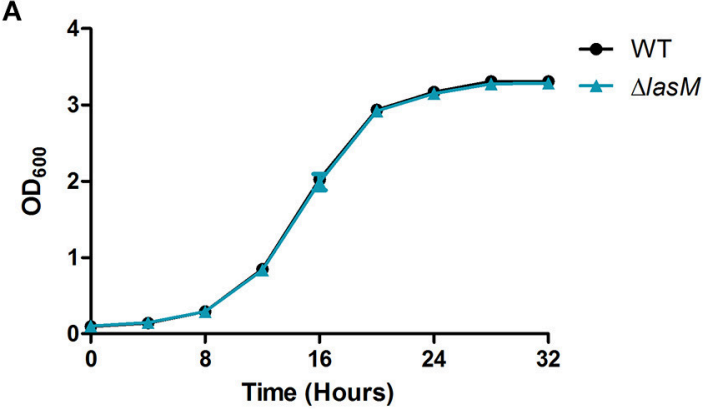

B

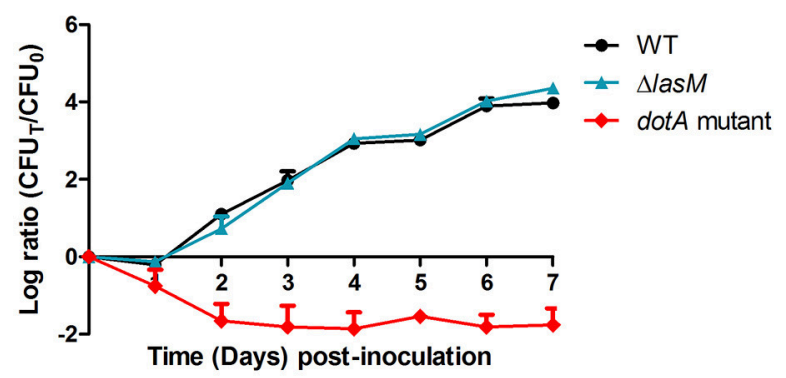

C

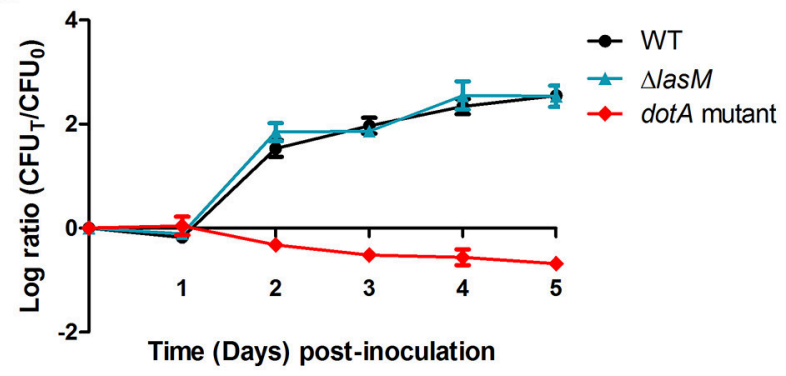

FIGURE 4 | Deletion of las $M$ does not affect the growth of $L p$ in vitro and in vivo. (A) Optical density at $600 \mathrm{~nm}$ of the WT and $\Delta / a s M$ strains grown in rich medium for $32 \mathrm{~h}$. (B) The amoeba A. castellanii or (C) cultured THP-1 macrophages were infected with the WT strain, $\Delta$ lasM or the dotA mutant (negative control) at an $\mathrm{MOI}$ of 0.1 . Changes in cell titer were monitored using daily CFU counts and are presented as the log ratio of the CFU on each day $\left(\mathrm{CFU}_{T}\right)$ over the initial $\mathrm{CFU}\left(\mathrm{CFU}_{0}\right)$. Data shown are the mean and SD of 3 biological replicates.

we compared the tolerance of the WT and $\Delta$ las $M$ strains in water at $55^{\circ} \mathrm{C}$. The CFU counts of both strains decreased to $42-47 \%$ of the initial population after $0.5 \mathrm{~h}$ and to $13-14 \%$ after $1 \mathrm{~h}$ of exposure to heat shock (Figure 6A). Increasing exposure time significantly reduced their CFU counts $(p<0.0001)$, but no significant differences were found between the two strains $(p=0.5605)$. Then, we compared the tolerance of both strains in rich medium at $42^{\circ} \mathrm{C}$ and, again, found no significant differences between their CFU counts over a period of 4 days (Figure 6B). Both strains grew in the first day and then their CFU counts dropped below the detection limit after 3 days. Taken together, these results suggest that deletion of las $M$ does not affect the tolerance of $L p$ to high temperature in water or in rich medium. 
A

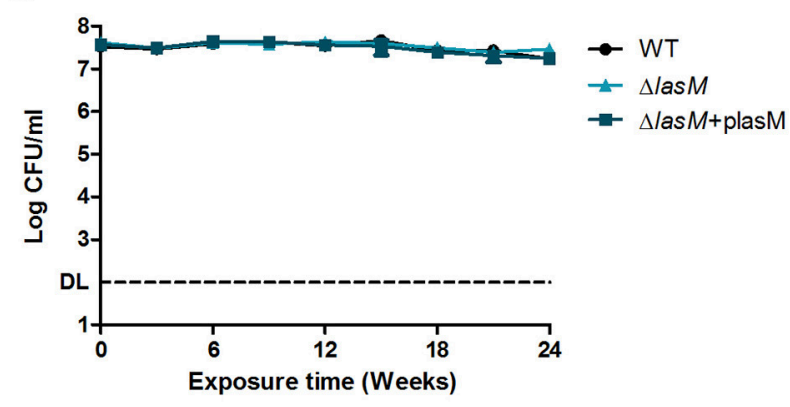

C

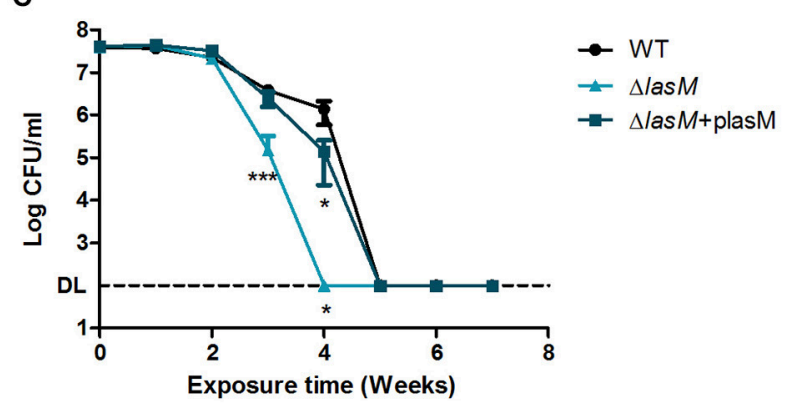

E

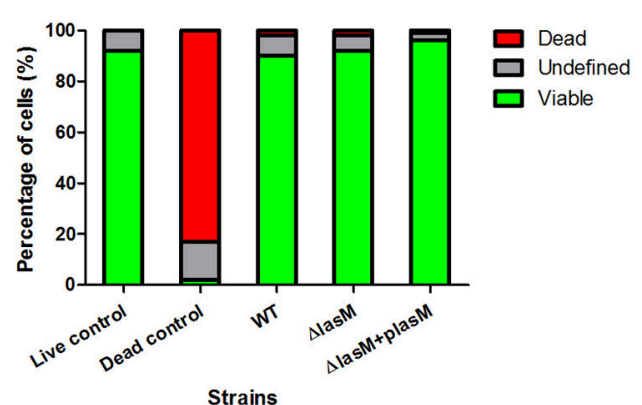

B

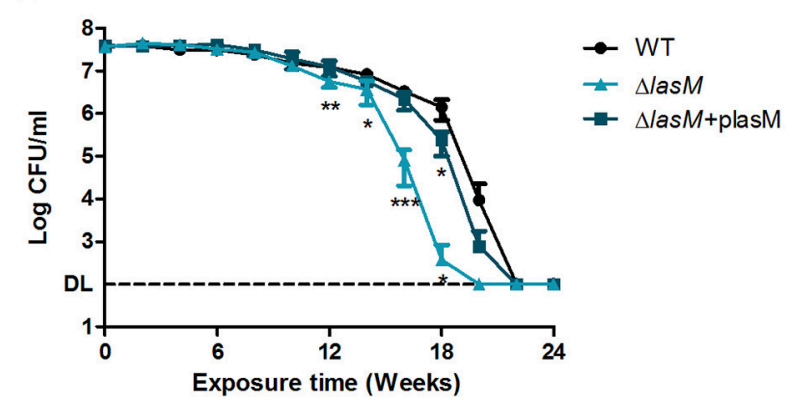

D

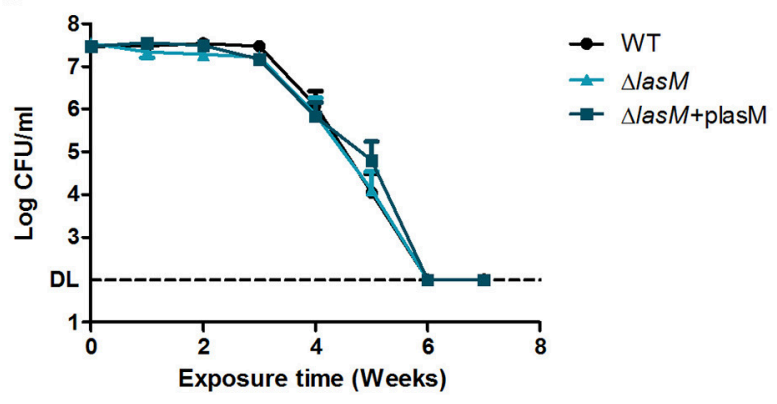

$\mathbf{F}$

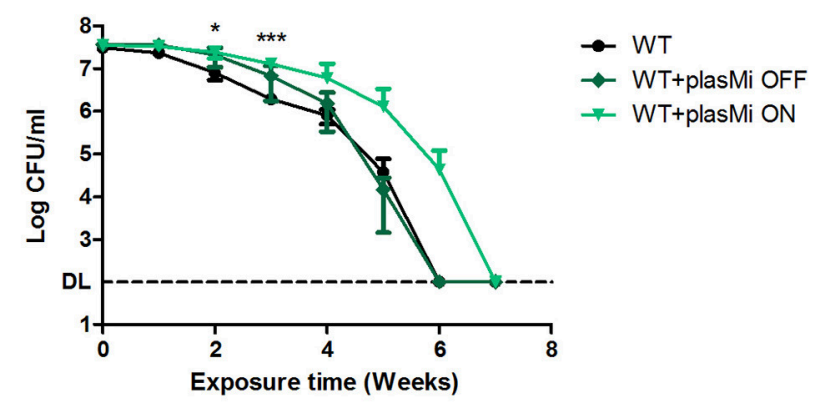

FIGURE 5 | Deletion and over-expression of las $M$ affects the culturability of $L p$ in water at 37 and $42^{\circ} \mathbf{C}$. The CFU counts of the WT, $\Delta / a s M$ and complemented strain ( $\Delta / a s M+$ plasM) in water at (A) $25^{\circ} \mathrm{C}$, (B) $37^{\circ} \mathrm{C}$, (C) $42^{\circ} \mathrm{C}$, and (D) in water with 10 times trace metals at $42^{\circ} \mathrm{C}$. (E) Percentage of cells in different status after exposure to water at $42^{\circ} \mathrm{C}$ for 7 weeks. Live/Dead staining and flow cytometry were used to analyze 5000 cells in each replicate. Freshly grown $L p$ was used as the live control and heat-killed $L p$ was used as the dead control. (F) CFU counts of the WT strain and the over-expression strain (WT+plasMi) in water at $42^{\circ} \mathrm{C}$. WT+plasMi OFF indicates that the over-expression of las $M$ was not induced, while WT+plasMi ON indicates that the over-expression of las $M$ was induced with $1 \mathrm{mM} \mathrm{IPTG}$. Data shown are the mean and SD of 3 biological replicates. One-tailed unpaired Student's $t$-test was used to assess significant differences against the WT $\left({ }^{\star} p<0.05 ;{ }^{* \star} p<0.005 ;{ }^{* \star *} p<0.0005\right)$. DL indicates the detection limit.

\section{DISCUSSION}

Despite the lack of nutrients, $L p$ can survive in freshwater for a prolonged period of time and also remain infectious (James et al., 1999; Li et al., 2015; Mendis et al., 2015). In this study, we characterize lpg1659 (lasM), a gene that encodes a hypothetical protein with no putative functions. In silico analysis shows that las $M$ encodes a membrane protein that is likely involved in transport and binding. Differential expression of membrane proteins are well documented in literature. In E. coli, some membrane proteins like OmpA and general porins are constitutively expressed at high levels, whereas other membrane proteins are only expressed under specific conditions (Koebnik et al., 2000). Exposure to water at varying temperatures elicited specific changes in the outer membrane protein composition of enterohemorrhagic E. coli (Wang and Doyle, 1998). In another waterborne pathogen Leptospira interrogans, the inner membrane protein LipL31 was specifically down-regulated during exposure to distilled water, while other membrane proteins were not affected (Trueba et al., 2004). In our case, 


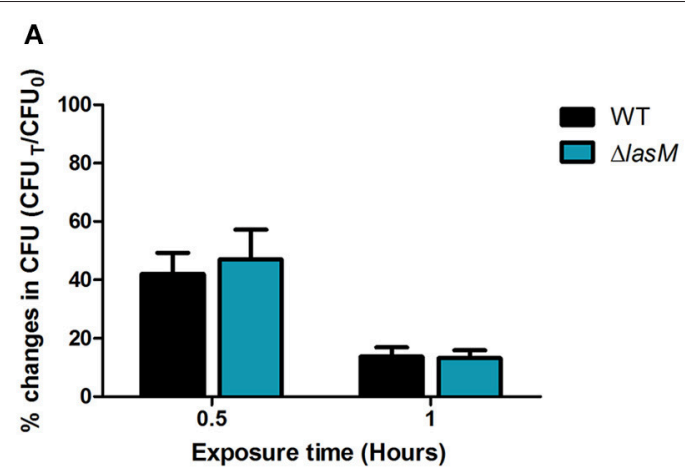

B

FIGURE 6 | Deletion of las $\boldsymbol{M}$ does not affect the tolerance of $\boldsymbol{L} \boldsymbol{p}$ to high temperature. (A) The WT strain and $\Delta / a s M$ were suspended in water and exposed to $55^{\circ} \mathrm{C}$ for 0.5 and $1 \mathrm{~h}$. The CFU counts after heat shock (CFU $)$ was compared to the CFU counts before heat shock (CFU $)$. (B) The WT strain and $\triangle$ lasM were grown in rich medium at $42^{\circ} \mathrm{C}$ and their daily CFU counts were monitored. Data shown are the mean and SD of 3 biological replicates. DL indicates the detection limit.

the expression of the LasM membrane protein was induced significantly after 2 and $6 \mathrm{~h}$ of exposure to water, compared to exponential growth in AYE (Li et al., 2015). A previous study showed that las $M$ is also induced in the post-exponential phase of growth (Hovel-Miner et al., 2009). Therefore, it is likely that a signal present in Fraquil and post-exponential phase, such as starvation, induces the expression of las $M$. Since $L p$ shuts down transcription and translation $24 \mathrm{~h}$ after exposure to water (Trigui et al., 2014; Li et al., 2015), genes required for survival in water are likely induced during earlier time points (i.e., the adaptation period), and are subsequently repressed. For example the $b d h A$ gene, encoding 3-hydroxybutyrate dehydrogenase, is required for the long-term survival of $L p$ in water, and follows this expression pattern (Li et al., 2015).

Since the alternative sigma factor RpoS is essential for $L p$ to survive in water (Trigui et al., 2014), any genes under the control of RpoS could also be involved in the survival of $L p$ in water. For example, $b d h A$ is positively regulated by RpoS in water and it was found to be important for the survival of $L p$ in water at $37^{\circ} \mathrm{C}(\mathrm{Li}$ et al., 2015). According to a previous study, las $M$ is positively regulated by RpoS in rich medium (Hovel-Miner et al., 2009). Here, we report that las $M$ is also under RpoS control when $L p$ is exposed to water, further suggesting an association between LasM and water survival.

Since LasM is predicted to be a membrane protein, we hypothesized that it may play a role in maintaining cell morphology or membrane integrity. However, deletion of las $M$ affected neither the cell shape nor size of freshly grown $L p$ that was suspended in water. Moreover, the membrane integrity of $L p$ exposed to water for 7 weeks was unaffected. We further found that deletion of las $M$ does not affect the ability of $L p$ to infect host cells such as A. castellanii and THP-1 cells. Furthermore, it does not affect the growth of Lp in vitro. This is consistent with a previous study showing that the insertion of a transposon in the las $M$ gene did not result in growth advantages or disadvantages in rich medium (O'Connor et al., 2011).

Nevertheless, we observed an early loss of culturability in $\Delta$ las $M$ exposed to water at 37 and $42^{\circ} \mathrm{C}$, suggesting that las $M$ is important for $L p$ to maintain culturability in warm water. These temperatures are commonly found in man-made water systems such as cooling towers that $L p$ is able to colonize (Rogers et al., 1994; Darelid et al., 2002). Live/Dead staining shows that the proportion of dead cell in the $\Delta$ las $M$ population is comparable to that of the WT, but the mutant enters a viable but non-culturable (VBNC) state earlier than the WT. VBNC cells are in a quiescent state awaiting revival or transitioning to death (Li et al., 2014). Previous studies show that $L p$ that was induced into the VBNC state under certain conditions, such as starvation and exposure to disinfectants, may be resuscitated back into culturable and infectious cells using different methods (reviewed by Li et al., 2014). For example, $L p$ that entered the VBNC status 125 days after exposure to sterilized tap water at $20^{\circ} \mathrm{C}$ were resuscitated by the addition of $A$. castellanii (Steinert et al., 1997). However, our attempt to resuscitate the samples using the same method failed and the VBNC cells remained non-infectious (data not shown). Differences in VBNC-inducing conditions (e.g., water, temperature, etc.) and additional factors may contribute to the failure of resuscitation (reviewed by $\mathrm{Li}$ et al., 2014). VBNC cells that cannot be resuscitated are considered to be in the process of dying. Therefore, we conclude that $\Delta$ las $M$ started dying at an earlier time point than the WT when exposed to water. Given that over-expression of LasM also promotes the culturability of $L p$ in water, we conclude that LasM is important for the long-term survival of $L p$ in water at temperatures above $25^{\circ} \mathrm{C}$.

Early loss of culturability was not observed in $\Delta$ las $M$ exposed to water at $25^{\circ} \mathrm{C}$ for 24 weeks. This is mirrored in a previous study where the deletion of $b d h A$ results in an early loss of culturability and causes a survival defect in $L p$ exposed to water at $37^{\circ} \mathrm{C}$ but not at $25^{\circ} \mathrm{C}$ ( $\mathrm{Li}$ et al., 2015). In both cases, it is possible that the survival defect becomes apparent at $25^{\circ} \mathrm{C}$ after a longer incubation period in water. Since CFU counts drop more gradually at $25^{\circ} \mathrm{C}$ than at 37 and $42^{\circ} \mathrm{C}$ (Mendis et al., 2015), any defect resulting from the deletion of an important gene may appear at a later time point at $25^{\circ} \mathrm{C}$.

Environmental stresses such as heat shock are known to increase membrane fluidity and eventually result in cell damage (Beney and Gervais, 2001; Richter et al., 2010). Therefore, it is 
possible that LasM is important for $L p$ to maintain culturability at a higher temperature, not necessarily in water. If the absence of the LasM membrane protein reduced the ability of $L p$ to deal with heat-induced membrane damage, the mutant would produce a faster drop in CFU counts than the WT at elevated temperatures. However, we show that deletion of las $M$ does not affect the rate of CFU reduction in $L p$ exposed to water at $55^{\circ} \mathrm{C}$ or the $\mathrm{CFU}$ changes in $L p$ grown in rich medium at $42^{\circ} \mathrm{C}$, suggesting that LasM is important for maintaining culturability in water, but that it is not directly involved in the resistance of $L p$ to high temperatures.

It is noteworthy that LasM was predicted to be a transporter, albeit with low probability $(p=0.409)$. Since the metabolic rate of $L p$ increases with increasing temperature (Kusnetsov et al., 1996), more energy and resources would be needed for active metabolism at higher temperatures. Therefore, if the function of LasM is to facilitate nutrient transport, then the loss of LasM could result in a more severe defect in water at $37^{\circ} \mathrm{C}$ or at $42^{\circ} \mathrm{C}$ than at $25^{\circ} \mathrm{C}$. Indeed, the absence of LasM did not affect the kinetics of culturability in water with 10 times the original amount of trace metals, suggesting that the early loss of culturability previously observed in the mutant can be complemented by excess trace metals in water, namely copper, molybdenum, cobalt, manganese, zinc, sodium and iron. This finding supports our hypothesis that LasM is a transporter of one or more of the essential trace metals present in water. In the absence of this transporter, $L p$ might not be able to acquire sufficient trace metals from water environment to maintain culturability, and possibly long-term survival. Our data show that over-expression of las $M$ in $L p$ seems to allow better acquisition of essential trace metals, helping to maintain culturability for a longer period of time. Extra trace metals in water might also increase the amount that diffused into cells, and thus, allow the mutant lacking LasM to maintain culturability as well as the WT. It is not yet clear which trace metal is transported by LasM. Based on our experiments, LasM could transport one or a combination of copper, molybdenum, cobalt, manganese, zinc and iron.

\section{REFERENCES}

Antony, C. P., Doronina, N. V., Boden, R., Trotsenko, Y. A., Shouche, Y. S., and Murrell, J. C. (2012). Methylophaga lonarensis sp. nov., a moderately haloalkaliphilic methylotroph isolated from the soda lake sediments of a meteorite impact crater. Int. J. Syst. Evol. Microbiol. 62, 1613-1618. doi: 10.1099/ijs.0.035089-0

Beney, L., and Gervais, P. (2001). Influence of the fluidity of the membrane on the response of microorganisms to environmental stresses. Appl. Microbiol. Biotechnol. 57, 34-42. doi: 10.1007/s002530100754

Charpentier, X., Faucher, S. P., Kalachikov, S., and Shuman, H. A. (2008). Loss of RNase $\mathrm{R}$ induces competence development in Legionella pneumophila. J. Bacteriol. 190, 8126-8136. doi: 10.1128/JB.01035-08

Chen, D.-Q., Huang, S.-S., and Lu, Y.-J. (2006). Efficient transformation of Legionella pneumophila by high-voltage electroporation. Microbiol. Res. 161, 246-251. doi: 10.1016/j.micres.2005.09.001

Darelid, J., Löfgren, S., and Malmvall, B. E. (2002). Control of nosocomial Legionnaires' disease by keeping the circulating hot water temperature above $55^{\circ} \mathrm{C}$ : experience from a 10 -year surveillance programme in a district general hospital. J. Hosp. Infect. 50, 213-219. doi: 10.1053/jhin.2002.1185
In conclusion, this study reveals that the LasM protein is important for $L p$ to acquire essential trace metals in order to maintain culturability in water, which is consistent with its most probable predicted function. Our results do not ruled out the possibility that LasM could increase the fitness of L. pneumophila in other settings where the concentration of metals is low or where there is fierce competition for them, such as multi-species biofilms existing in water systems. The las $M$ gene is highly upregulated in water and positively regulated by RpoS. It encodes a novel membrane protein, which is highly conserved in many Legionella species and other aquatic bacteria. We postulate that LasM is an important protein for other aquatic bacteria to maintain culturability and survival in water and in conditions presenting low concentration of metals. Absence of this protein does not affect cell morphology, membrane integrity, tolerance to high temperature or the growth of $L p$, both in vitro and in vivo. Further investigation would be required to better understanding the exact trace metal(s) being transported by LasM and the underlying mechanism.

\section{AUTHOR CONTRIBUTIONS}

LL and SF conceived and designed the experiments. LL conducted the experiments and wrote the manuscript. SF contributed in writing and review of the manuscript.

\section{FUNDING}

This work was supported by the NSERC Discovery grant 418289 2012 and John R. Evans Leaders Fund-Funding for research infrastructure from the Canadian Foundation for Innovation to SF.

\section{ACKNOWLEDGMENTS}

We would like to thank Nilmini Mendis for reviewing the manuscript and English editing.

de Felipe, K. S., Glover, R. T., Charpentier, X., Anderson, O. R., Reyes, M., Pericone, C. D., et al. (2008). Legionella eukaryotic-like type IV substrates interfere with organelle trafficking. PLoS Pathogens 4:e1000117. doi: 10.1371/journal.ppat.1000117

Edelstein, P. H. (1981). Improved semiselective medium for isolation of Legionella pneumophila from contaminated clinical and environmental specimens. J. Clin. Microbiol. 14, 298-303.

European Centre for Disease Prevention and Control (2013). Annual Epidemiological Report 2013: Reporting on 2011 Surveillance Data and 2012 Epidemic Intelligence Data. Stockholm: ECDC.

Faucher, S. P., Mueller, C. A., and Shuman, H. A. (2011). Legionella pneumophila transcriptome during intracellular multiplication in human macrophages. Front. Microbiol. 2:60. doi: 10.3389/fmicb.2011. 00060

Feeley, J. C., Gibson, R. J., Gorman, G. W., Langford, N. C., Rasheed, J. K., Mackel, D. C., et al. (1979). Charcoal-yeast extract agar: primary isolation medium for Legionella pneumophila. J. Clin. Microbiol. 10, 437-441.

Fields, B. S., Benson, R. F., and Besser, R. E. (2002). Legionella and Legionnaires' disease: 25 years of investigation. Clin. Microbiol. Rev. 15, 506-526. doi: 10.1128/CMR.15.3.506-526.2002 
Hales, L. M., and Shuman, H. A. (1999). The Legionella pneumophila rpoS gene is required for growth within Acanthamoeba castellanii. J. Bacteriol. 181, 4879-4889.

Handley, K. M., Héry, M., and Lloyd, J. R. (2009). Marinobacter santoriniensis sp. nov., an arsenate-respiring and arsenite-oxidizing bacterium isolated from hydrothermal sediment. Int. J. Syst. Evol. Microbiol. 59, 886-892. doi: 10.1099/ ijs.0.003145-0

Hecker, M., Reder, A., Fuchs, S., Pagels, M., and Engelmann, S. (2009). Physiological proteomics and stress/starvation responses in Bacillus subtilis and Staphylococcus aureus. Res. Microbiol. 160, 245-258. doi: 10.1016/j.resmic. 2009.03.008

Hovel-Miner, G., Pampou, S., Faucher, S. P., Clarke, M., Morozova, I., Morozov, P., et al. (2009). $\sigma^{\mathrm{S}}$ controls multiple pathways associated with intracellular multiplication of Legionella pneumophila. J. Bacteriol. 191, 2461-2473. doi: 10.1128/JB.01578-08

Ishihama, A. (2000). Functional modulation of Escherichia coli RNA polymerase. Annu. Rev. Microbiol. 54, 499-518. doi: 10.1146/annurev.micro.54.1.499

James, B. W., Mauchline, W. S., Dennis, P. J., Keevil, C. W., and Wait, R. (1999). Poly-3-hydroxybutyrate in Legionella pneumophila, an energy source for survival in low-nutrient environments. Appl. Environ. Microbiol. 65, 822-827.

Jensen, L. J., Gupta, R., Blom, N., Devos, D., Tamames, J., Kesmir, C., et al. (2002). Prediction of human protein function from post-translational modifications and localization features. J. Mol. Biol. 319, 1257-1265. doi: 10.1016/S00222836(02)00379-0

Jensen, L. J., Gupta, R., Stærfeldt, H.-H., and Brunak, S. (2003). Prediction of human protein function according to Gene Ontology categories. Bioinformatics 19, 635-642. doi: 10.1093/bioinformatics/btg036

Kim, E.-H., Charpentier, X., Torres-Urquidy, O., McEvoy, M. M., and Rensing, C. (2009). The metal efflux island of Legionella pneumophila is not required for survival in macrophages and amoebas. FEMS Microbiol. Lett. 301, 164-170. doi: 10.1111/j.1574-6968.2009.01813.x

Kim, H. J., Park, S., Lee, J. M., Park, S., Jung, W., Kang, J.-S., et al. (2008). Moritella dasanensis sp. nov., a psychrophilic bacterium isolated from the Arctic ocean. Int. J. Syst. Evol. Microbiol. 58, 817-820. doi: 10.1099/ijs.0.65501-0

Koebnik, R., Locher, K. P., and Van Gelder, P. (2000). Structure and function of bacterial outer membrane proteins: barrels in a nutshell. Mol. Microbiol. 37, 239-253. doi: 10.1046/j.1365-2958.2000.01983.x

Krogh, A., Larsson, B., Von Heijne, G., and Sonnhammer, E. L. L. (2001). Predicting transmembrane protein topology with a hidden Markov model: application to complete genomes. J. Mol. Biol. 305, 567-580. doi: 10.1006/jmbi.2000.4315

Kurahashi, M., and Yokota, A. (2007). Endozoicomonas elysicola gen. nov., sp. nov., a $\gamma$-proteobacterium isolated from the sea slug Elysia ornata. Syst. Appl. Microbiol. 30, 202-206. doi: 10.1016/j.syapm.2006.07.003

Kusnetsov, J. M., Ottoila, E., and Martikainen, P. J. (1996). Growth, respiration and survival of Legionella pneumophila at high temperatures. J. Appl. Bacteriol. 81, 341-347. doi: 10.1111/j.1365-2672.1996.tb03517.x

Lee, J., and West, A. (1991). Survival and growth of Legionella species in the environment. J. Appl. Bacteriol. 70, 121S-129S.

Li, L., Mendis, N., Trigui, H., and Faucher, S. P. (2015). Transcriptomic changes of Legionella pneumophila in water. BMC Genomics 16:637. doi: 10.1186/s12864015-1869-6

Li, L., Mendis, N., Trigui, H., Oliver, J. D., and Faucher, S. P. (2014). The importance of the viable but non-culturable state in human bacterial pathogens. Front. Microbiol. 5:258. doi: 10.3389/fmicb.2014.00258

Livak, K. J., and Schmittgen, T. D. (2001). Analysis of relative gene expression data using real-time quantitative PCR and the $2^{\Delta \Delta C T}$ method. Methods $25,402-408$. doi: 10.1006/meth.2001.1262

Mendis, N., McBride, P., and Faucher, S. P. (2015). Short-term and long-term survival and virulence of Legionella pneumophila in the defined freshwater medium Fraquil. PLoS ONE 10:e0139277. doi: 10.1371/journal.pone.0139277

Moffat, J. F., and Tompkins, L. S. (1992). A quantitative model of intracellular growth of Legionella pneumophila in Acanthamoeba castellanii. Infect. Immun. 60, 296-301.

Morel, F. M., Westall, J. C., Reuter, J., and Chaplick, J. P. (1975). "Description of the algal growth media 'Aquil' and 'Fraquil', in Technical Report 16 (Cambridge: Massachusetts Institute of Technology).
O’Connor, T. J., Adepoju, Y., Boyd, D., and Isberg, R. R. (2011). Minimization of the Legionella pneumophila genome reveals chromosomal regions involved in host range expansion. Proc. Natl. Acad. Sci. U.S.A. 108, 14733-14740. doi: 10.1073/pnas.1111678108

Paszko-Kolva, C., Shahamat, M., and Colwell, R. R. (1992). Long-term survival of Legionella pneumophila serogroup 1 under low-nutrient conditions and associated morphological changes. FEMS Microbiol. Lett. 102, 45-55. doi: 10.1111/j.1574-6968.1992.tb05794.x

Petersen, T. N., Brunak, S., Von Heijne, G., and Nielsen, H. (2011). SignalP 4.0: discriminating signal peptides from transmembrane regions. Nat. Methods 8, 785-786. doi: 10.1038/nmeth.1701

Phin, N., Parry-Ford, F., Harrison, T., Stagg, H. R., Zhang, N., Kumar, K., et al. (2014). Epidemiology and clinical management of Legionnaires' disease. Lancet Infect. Dis. 14, 1011-1021. doi: 10.1016/S1473-3099(14)70713-3

Richter, K., Haslbeck, M., and Buchner, J. (2010). The heat shock response: life on the verge of death. Mol. Cell 40, 253-266. doi: 10.1016/j.molcel.2010.10.006

Rogers, J., Dowsett, A. B., Dennis, P. J., Lee, J. V., and Keevil, C. W. (1994). Influence of temperature and plumbing material selection on biofilm formation and growth of Legionella pneumophila in a model potable water system containing complex microbial flora. Appl. Environ. Microbiol. 60, 1585-1592.

Roy, C. R., and Isberg, R. R. (1997). Topology of Legionella pneumophila DotA: an inner membrane protein required for replication in macrophages. Infect. Immun. 65, 571-578.

Sadosky, A. B., Wiater, L. A., and Shuman, H. A. (1993). Identification of Legionella pneumophila genes required for growth within and killing of human macrophages. Infect. Immun. 61, 5361-5373.

Schofield, G. M. (1985). A note on the survival of Legionella pneumophila in stagnant tap water. J. Appl. Bacteriol. 59, 333-335. doi: 10.1111/j.13652672.1985.tb03327.x

Skaliy, P., and McEachern, H. V. (1979). Survival of the Legionnaires' disease bacterium in water. Ann. Intern. Med. 90, 662-663. doi: 10.7326/0003-481990-4-662

Söderberg, M. A., Dao, J., Starkenburg, S. R., and Cianciotto, N. P. (2008). Importance of type II secretion for survival of Legionella pneumophila in tap water and in amoebae at low temperatures. Appl. Environ. Microbiol. 74, 5583-5588. doi: 10.1128/AEM.00067-08

Sonnhammer, E. L. L., von Heijne, G., and Krogh, A. (1998). “A hidden Markov model for predicting transmembrane helices in protein sequences," in ISMB 1998 Proceedings (Menlo Park, CA: AAAI Press), 175-182.

Steinert, M., Emödy, L., Amann, R., and Hacker, J. (1997). Resuscitation of viable but nonculturable Legionella pneumophila Philadelphia JR32 by Acanthamoeba castellanii. Appl. Environ. Microbiol. 63, 2047-2053.

Trigui, H., Dudyk, P., Oh, J., Hong, J.-I., and Faucher, S. P. (2014). A regulatory feedback loop between RpoS and SpoT supports the survival of Legionella pneumophila in water. Appl. Environ. Microbiol. 81, 918-928. doi: 10.1128/ AEM.03132-14

Trueba, G., Zapata, S., Madrid, K., Cullen, P., and Haake, D. (2004). Cell aggregation: a mechanism of pathogenic Leptospira to survive in fresh water. Int. Microbiol. 7, 35-40.

Villeneuve, C., Martineau, C., Mauffrey, F., and Villemur, R. (2013). Methylophaga nitratireducenticrescens sp. nov. and Methylophaga frappieri sp. nov., isolated from the biofilm of the methanol-fed denitrification system treating the seawater at the Montreal Biodome. Int. J. Syst. Evol. Microbiol. 63, 2216-2222. doi: 10.1099/ijs.0.044545-0

Wang, G., and Doyle, M. P. (1998). Survival of enterohemorrhagic Escherichia coli O157:H7 in water. J. Food Prot. 61, 662-667.

Conflict of Interest Statement: The authors declare that the research was conducted in the absence of any commercial or financial relationships that could be construed as a potential conflict of interest.

Copyright (C) $2016 \mathrm{Li}$ and Faucher. This is an open-access article distributed under the terms of the Creative Commons Attribution License (CC BY). The use, distribution or reproduction in other forums is permitted, provided the original author (s) or licensor are credited and that the original publication in this journal is cited, in accordance with accepted academic practice. No use, distribution or reproduction is permitted which does not comply with these terms. 